¿Qué barbaridad!

Einführung in die spanische Sprache

Lehrerheft - Schlüssel zu den Ưbungen 

Albert Fuß/Felipe Jambrina / Angel San Miguel

\section{¡Qué barbaridad!}

Einführung in die spanische Sprache

Lehrerheft

Schlüssel zu den Übungen

Max Niemeyer Verlag

Tübingen 1981 
CIP-Kurztitelaufnahme der Deutschen Bibliothek

Fuss, Albert:

Qué barbaridad! Einf. in d. span. Sprache / Albert Fuss ; Felipe Jambrina ; Angel San Miguel. - Tübingen : Niemeyer

NE: Jambrina, Felipe; San Miguel, Angel:

San-Miguel, Angel

Lehrerh. Schlüssel zu den Übungen. - 1981.

ISBN 3-484-50186-3

(C) Max Niemeyer Verlag Tübingen 1981

Alle Rechte vorbehalten. Ohne ausdrückliche Genehmigung des Verlages ist es nicht gestattet, das Buch oder Teile daraus auf photomechanischem Wege zu vervielfaltigen. Printed in Germany. Druck: fotokop Wilhelm Weihert KG, Darmstadt. 